\title{
Insights from Small-N Studies
}

Julia Gouvea*

Tufts University, Medford, MA 02155
$\mathrm{S}_{\mathrm{ar} \text { e }}^{\mathrm{m}}$ mall- $N$ studies ${ }^{1}$ have been relatively uncommon in biology education research and likely less familiar to instructors and administrators than large- $N$ studies. Nevertheless, many scholars in the social sciences have argued for the value of small- $N$ studies in informing research and practice (e.g., Flyvbjerg, 2006). As in medical research, small- $N$ case studies allow for deep examinations of phenomena in real-life contexts, shedding light on the underlying mechanisms and providing a rich basis for practitioner knowledge.

This group of recent papers illustrates how small- $N$ studies can make contributions to education research and practice. Each explores and proposes new ways of thinking about familiar concepts (e.g., identity, nature of science, emotion, self-efficacy) and builds theoretical connections among them in order to explain student learning. In doing so, these studies raise new questions that can drive forward emerging research paradigms in biology education research (Dolan, 2015) and provide thought-provoking implications for biology instruction.

Quan, G. M., \& Elby, A. (2016). Connecting self-efficacy and views about the nature of science in undergraduate research experiences. Physical Review Special Topics_Physics Education Research, 12, 20140. http://doi.org/10.1103/ PhysRevPhysEducRes.12.020140

An increasingly important goal of biology education is to support students' developing confidence as scientific researchers-their self-efficacy for scientific research (e.g., Ainscough et al., 2016; Olimpo et al., 2016). Participation in undergraduate research is expected to increase students' self-efficacy, and students frequently self-report increased feelings of confidence after such experiences (Seymour et al., 2004). So is shifting self-efficacy simply a matter of providing students with more research experiences? Quan and Elby conducted case study analyses to explore potential mechanisms underlying this link.

The context of their study was an undergraduate research program for physics majors. Students conducted research mentored by a faculty member and attended a weekly group seminar. Quan and Elby used interviews and recorded discussions from the seminar to explore shifts in self-efficacy in these students. Through an analysis of data from three students, the authors propose a "tentative directional link" between self-efficacy and students' ideas about the nature of scientific research.

Two cases illustrate the directional link. While they differ in the details, each describes a student's shift from expecting scientific research to be driven by infallible experts to seeing research as a collaborative endeavor involving uncertainty and improvisation. In both cases, these shifts in understanding the nature of scientific research made space for the undergraduate students to feel like they could meaningfully contribute within the research community. A third contrasting case illustrates how a lack of shift in self-efficacy was linked to a lack of productive views on the nature of scientific research.

${ }^{1}$ By small- $N$ studies, I mean studies that examine one or a few individuals (typically fewer than five). Timescales of such studies can range from analyses of moments to years, and typically employ one or more qualitative methods (e.g., ethnography or discourse analysis). What unites small- $N$ studies is that they seek to investigate chosen cases in depth and in context, rather than making statistical claims based on large numbers.
CBE Life Sci Educ September 1, 2017 16:fe4 DOI:10.1187/cbe.17-06-0110

This feature is designed to point CBE-Life Sciences Education readers to current or noteworthy articles for life science educators and education researchers. We invite readers to suggest current themes or articles of interest in life science education as well as influential papers published in the more distant past or in the broader field of education research to be featured in Current Insights. Please send any suggestions to Julia.Gouvea@tufts.edu.

*Address correspondence to: Julia Gouvea (Julia Gouvea(tufts.edu).

(C) 2017 J. Gouvea. CBE-Life Sciences Education (C) 2017 The American Society for Cell Biology. This article is distributed by The American Society for

Cell Biology under license from the author(s). It is available to the public under an Attribution-Noncommercial-Share Alike 3.0 Unported Creative Commons License (http://creativecommons .org/licenses/by-nc-sa/3.0).

"ASCB®" and "The American Society for Cell Biology ${ }^{\circledR}$ " are registered trademarks of The American Society for Cell Biology. 
Quan and Elby use these cases to argue for a novel conceptualization of self-efficacy in scientific research: it is not just the degree to which students see themselves as capable of doing science; it is also how they understand the practice of science itself. The authors argue that this coupling raises questions and concerns for science education researchers. They show how, for example, it complicates interpretations of self-efficacy reported on survey instruments. A student's self-reported increase in self-efficacy related to some aspect of scientific research could be interpreted in two ways. In one interpretation, the student has become more confident in his or her abilities. In a second interpretation, the student has changed his or her understanding of what that aspect of scientific research entails, possibly reframing it as something he or she could already do.

The two interpretations represent different mechanisms for increasing students' self-efficacy in scientific research and have different implications for instruction. The former suggests a need to focus on building confidence; the latter a focus on how we represent scientific research and position students within it.

Jaber, L. Z., \& Hammer, D. (2016). Learning to feel like a scientist. Science Education, 100(2), 189-220. http://doi .org/10.1002/sce.21202

Recently, the biology education community has begun to place more emphasis on understanding the role of students' interests, motivations, and emotions as related to their learning (e.g., Lovelace and Brickman, 2013; Trujillo and Tanner, 2014). Much of this research demonstrates correlations between affect and/or motivation and performance. We know less about the origins of students' affective responses, how they develop over time, or how to cultivate them.

Jaber and Hammer present a case study of a young girl, Sandra, who described herself as so interested in science that she was "hooked in." Their aim in studying Sandra's case was to gain insight into the mechanisms that fostered this interest. Through analyses of classroom episodes from Sandra's fourth- and fifth-grade science classes and interviews with Sandra in sixth and seventh grade, the authors describe how Sandra's affect and motivation (feelings of joy, ownership, persistence) were tied up in her disciplinary contributions (arguments, discussions, and experiments in her science classes). In one example, they describe how Sandra was captivated by the challenge of using a magnet to generate motion. In another episode, they describe her persistence in understanding a fellow classmate's ideas about where water goes when it evaporates.

Analyses of moments like these show that Sandra's interest in science emerged not just because her science class was "fun" in a general way, but because Sandra was excited by and drawn into the intellectual work. The authors define the affect and motivation in these moments as epistemic to emphasize that they are tied to the production and evaluation of scientific knowledge. They conjecture that repeated experiences of intertwined emotional and epistemic work within science could give rise to more stable interests toward science.

For researchers, this article underscores the need to investigate how moments of epistemic affect and motivation emerge and to understand the impact such moments have over time.
For practitioners, this article proposes the need to design learning environments that cultivate feelings of joy, frustration, or passion as central to the work of learning to do science.

Danielak, B. A., Gupta, A., \& Elby, A. (2014). The marginalized identities of sense-makers: Reframing engineering student retention. Journal of Engineering Education, 103(1), 8-44. http://doi.org/10.1002/jee.20035

The final paper in this set uses a case study analysis to propose a new way to think about the problem of student retention in science, technology, engineering, and mathematics (STEM) fields. Prior research has reported on associations between retention and students' identification with, and sense of belonging in, STEM disciplines (e.g., Hunter et al., 2007; Nostrand and Pollenz, 2017).

Danielak, Gupta, and Elby propose the need to draw attention to the epistemological dimension of identity-how one thinks about oneself as a knower and learner. They present the case of Michael, an engineering student, whose identification as a "sense-maker"—someone who actively seeks deeper conceptual understanding - contributed to his feeling marginalized in an engineering program.

Using interviews and ethnographic observations, the authors make a series of interrelated claims: 1) Sense-making was an integral part of Michael's identity; 2) Michael perceived the culture of the engineering department, with its focus on computational correctness, to be at odds with this identity; 3) this mismatch created a tension for Michael that caused him to feel "punished" and marginalized within his engineering major; and 4) this tension was enough to cause Michael to consider leaving the major.

The authors acknowledge that Michael is not a "typical" engineering student. He is, in fact, a very high-achieving student, extremely reflective, and uncommonly articulate about his own approach to learning. For that very reason, they argue, if a student like Michael is feeling pushed out of engineering, a closer look at what is happening for other students is warranted. In this way, Michael's case is "revelatory," in that it draws attention to the understudied relationship between the epistemological aspects of learners' identities and their sense of belonging in and trajectories through programs of study.

The authors end by proposing an expanded notion of retention: "We argue that retention in engineering education should encompass both students and practices. In other words, improving retention should not be simply an effort to attract and retain more people; it should also be a mission to encourage and sustain engineering's core disciplinary practices through pedagogy" (p. 34).

In biology education, we might ask not just how many students we are moving through the biology major, but also what kinds of learning experiences within biology are drawing students' attention and interest? How does what matters to students align with what they perceive as valued by courses and programs?

In closing, these papers illustrate two ways small- $N$ studies contribute to education research: by refining definitions of familiar concepts and by proposing tentative hypotheses about relationships among them. These contributions can productively complicate and complement the knowledge we gain from large- $N$ studies by challenging us to reconsider what we 
may (or may not) be measuring and by illuminating possible mechanisms underlying statistical correlations. Furthermore, the rich descriptions provided by small- $N$ studies can deepen our collective expertise as practitioners by providing glimpses into the complex reality of how learning to participate in science unfolds for individual students.

\section{URLs are provided for the abstracts or full text of articles.}

\section{REFERENCES}

Ainscough, L., Foulis, E., Colthorpe, K., Zimbardi, K., Robertson-Dean, M. Chunduri, P., \& Lluka, L. (2016). Changes in biology self-efficacy during a first-year university course. CBE-Life Sciences Education, 15(2), ar19. http://doi.org/10.1187/cbe.15-04-0092

Dolan, E. L. (2015). Biology education research 2.0. CBE-Life Sciences Education, 14(4), ed1. http://doi.org/10.1187/cbe.15-11-0229

Flyvbjerg, B. (2006). Five misunderstandings about case-study research. Qualitative Inquiry, 12(2), 219-245. http://doi.org/10.1177/1077800405284363

Hunter, A.-B., Laursen, S. L., \& Seymour, E. (2007). Becoming a scientist: The role of undergraduate research in students' cognitive, personal, and professional development. Science Education, 91(1), 36-74. http://doi org/10.1002/sce.20173

Lovelace, M., \& Brickman, P. (2013). Best practices for measuring students attitudes toward learning science. CBE-Life Sciences Education, 12(4), 606-617. http://doi.org/10.1187/cbe.12-11-0197

Nostrand, D. F.-V., \& Pollenz, R. S. (2017). Evaluating psychosocial mechanisms underlying STEM persistence in undergraduates: Evidence of impact from a six-day pre-college engagement STEM academy program. CBE-Life Sciences Education, 16(2), ar36. http://doi.org/10.1187/cbe.16 $-10-0294$

Olimpo, J. T., Fisher, G. R., \& Dechenne-Peters, S. E. (2016). Development and evaluation of the Tigriopus course-based undergraduate research experience: Impacts on students' content knowledge, attitudes, and motivation in a majors introductory biology course. CBE-Life Sciences Education, 15(4), ar72. http://doi.org/10.1187/cbe.15-11-0228

Seymour, E., Hunter, A.-B., Laursen, S. L., \& DeAntoni, T. (2004). Establishing the benefits of research experiences for undergraduates in the sciences: First findings from a three-year study. Science Education, 88(4), 493534. http://doi.org/10.1002/sce.10131

Trujillo, G., \& Tanner, K. D. (2014). Considering the role of affect in learning Monitoring students' self-efficacy, sense of belonging, and science identity. CBE-Life Sciences Education, 13(1), 6-15. http://doi.org/10.1187/ cbe.13-12-0241 